\title{
Risk of falls and fear of falling in older adults residing in public housing in Ontario, Canada: findings from a multisite observational study
}

\author{
Melissa Pirrie ${ }^{1}$, Guneet Saini ${ }^{2}$, Ricardo Angeles ${ }^{1}$, Francine Marzanek ${ }^{1}$, Jenna Parascandalo ${ }^{1}$ and Gina Agarwal ${ }^{1,2^{*}}$ (D)
}

\begin{abstract}
Background: Falls in older adults is a widely researched topic. However, older adults residing in public housing are a vulnerable population that may have unique risk factors for falls. This study aims to describe the prevalence and risk factors for falls, fear of falling, and seeking medical attending for falls in this population.

Methods: Sociodemographic and health-related data was collected as part of a community-based health assessment program with older adults in public housing. Three pre-screening questions identified individuals at potential risk for falls; individuals who screened positive performed the objective Timed Up and Go (TUG) test. Logistic regression was used to evaluate risk factors for four outcome variables: falls in the past year, seeking medical attention for falls, fear of falling, and objectively measured fall risk via TUG test.
\end{abstract}

Results: A total of 595 participants were evaluated, of which the majority were female (81.3\%), white (86.7\%), did not have a high school diploma (50.0\%), and reported problems in mobility (56.2\%). The prevalence of falls in the past year was 34.5\%, seeking medical attention for falls was $20.2 \%$ and fear of falling was $38.8 \%$. The TUG test was completed by 257 participants. Notably, males had significantly reduced odds of seeking medical attention for a fall $(\mathrm{OR}=0.50,95 \% \mathrm{Cl} 0.25-0.98)$ and having a fear of falling $(\mathrm{OR}=0.42,95 \% \mathrm{Cl} 0.24-0.76)$; daily fruit and vegetable consumption was associated with decreased odds of having a fall in the past year ( $\mathrm{OR}=0.55,95 \% \mathrm{Cl} 0.37-0.83)$, and alcohol consumption was associated with increased odds of fear of falling $(\mathrm{OR}=1.72,95 \% \mathrm{Cl} 1.03-2.88)$.

Conclusion: Older adults residing in public housing have unique risk factors associated with social determinants of health, such as low fruit and vegetable consumption, which may increase their risk for falls. The findings of this study can be used to inform falls interventions for this population and identify areas for further research.

Keywords: Older adults, Public housing, Fall risk, Fear of falling, Low income, Social determinants of health

\section{Background}

According to the 2008-2009 Canadian Community Health Survey, approximately 1 in 5 Canadians over the age of 65 experienced a fall in the previous year [1]. In those who sustained an injury, approximately $45.1 \%$ received medical attention and $26.6 \%$ required hospitalization. Some of the injuries included bone fractures (8.4\%), head injuries (3.0\%)

\footnotetext{
* Correspondence: gina.agarwal@gmail.com

1 Department of Family Medicine, McMaster University, David Braley Health Sciences Centre, 100 Main Street West, 5th Floor, Hamilton, ON L8P 1H6, Canada

${ }^{2}$ Department of Health Research Methods, Evidence, and Impact, McMaster University, 1280 Main Street West, Hamilton, ON L8S 4L8, Canada
}

and sprains or strains (9.9\%) [1]. Compared to the length of stay for seniors admitted for all causes, fall-related hospitalization is, on average, nine days longer [2]. Additionally, older adults hospitalized for a fall are more likely to be moved into long-term care than those hospitalized for other reasons [3]. This results in a loss of independence for the individual and increased costs for the healthcare system due to fall-related injuries.

The prevalence of falls and 'fear of falling' have been extensively studied in the general population of community-dwelling older adults. Previous studies have found factors such as falls in the previous year, age,

(c) The Author(s). 2020 Open Access This article is distributed under the terms of the Creative Commons Attribution 4.0 International License (http://creativecommons.org/licenses/by/4.0/), which permits unrestricted use, distribution, and reproduction in any medium, provided you give appropriate credit to the original author(s) and the source, provide a link to the Creative Commons license, and indicate if changes were made. The Creative Commons Public Domain Dedication waiver (http://creativecommons.org/publicdomain/zero/1.0/) applies to the data made available in this article, unless otherwise stated. 
gender, ethnicity, educational level, body mass index, household income, chronic diseases, depression, pain and visual impairment to be associated with fear of falling $[4,5]$. In a systematic review, Deandrea et al. [6] examined the association of over 30 factors with risk of falling as identified within 74 prospective cohort studies. Sociodemographic variables such as age, sex, history of falls, physical activity, physical disability, visual impairment, instrumental disability, education, and walking aid use were associated with falls [6]. Moreover, medical and psychological factors including depression, comorbidities, antihypertensive medication, self-perceived poor health, fear of falling and Parkinson disease were associated with an increased risk of falling [6].

Older adults living in public housing are a vulnerable population with low socioeconomic status, low education, and low health literacy [7]. Low-income older adults report poorer physical and mental health compared to the general population of community-dwelling older adults [7]. Based on the available studies [4-6], it is expected there will be a higher prevalence of falls in this population, but this remains a gap in the literature. Also, the risk factors associated with falling and fear of falling in this population may deviate from those observed in the general population, but this has not been evaluated. Finally, low-income older adults may be more likely to seek medical attention based on their general patterns of health care utilization $[3,8,9]$. The association between low socioeconomic status (SES) and a high number of emergency department (ED) visits and subsequent hospitalization has been well documented among community-dwelling elderly $[8,9]$. It has also been shown that older adults with a lower SES have a longer length of hospitalization than those with a high SES and having poor health prior to hospitalization predicts a worse trajectory post-fall $[3,9]$. Therefore, it is important to determine the prevalence of and risk factors for falls, fear of falling, and seeking medical attention for falls in this vulnerable population.

Using baseline data from an existing cardiovascular health assessment program across Ontario, this crosssectional study aimed to better understand the prevalence of falling, receiving medical attention for falls, fear of falling and objectively measured fall risk among older adults residing in public housing. Additionally, the risk factors associated with each of these outcomes was determined, an area of research that is currently unexplored. The findings from this study could be used to inform and evaluate safety and falls prevention initiatives for older adults that are offered through public health programming.

\section{Methods}

\section{Study setting and participants}

Using a cross-sectional design, this study used baseline data collected through assessments as part of the randomized control trial for the Community Paramedicine at Clinic (CP@clinic) program [10]. CP@clinic is a weekly health promotion and health prevention drop-in program designed to target low-income seniors in public housing buildings, in order to assess modifiable risk factors for health conditions, educate participants and then link them to resources in their community.

The participants in this study consisted of older adults aged 55 and older residing in public housing buildings within five communities in Ontario, Canada (Hamilton, Guelph, Simcoe County, Sudbury, and York) who underwent health assessments by community paramedics from 2013 to 2015 . A total of 595 residents attended the CP@clinic program. The study population represents community-dwelling adults of low socioeconomic status in public housing. For most Ontario public housing providers, 55 is the minimum age for residing in buildings designated for seniors.

\section{Measures}

AllCP@clinic participants were asked three screening questions recommended for identifying fall risk in older adults by primary care: "Have you fallen in the last year?", "Have you sought medical attention for a fall?" and "Do you have a fear of falling?" [11, 12]. Participants who answered yes to at least one question were objectively assessed for fall risk using the Timed Up and Go (TUG) test, a validated screening measure for identifying older adults at risk of falling [13]. This test consists of an individual being initially seated in a chair, standing up, walking to a marked line $3 \mathrm{~m}$ away, turning around, walking back to the chair, and sitting down. If the participant failed to complete this test within $14 \mathrm{~s}$, they were considered to be at risk of falling. TUG test scores (in seconds) were recoded as either at risk (over 14s) or not at risk (14 s or less) [11, 12].

Health-related indicators collected by the paramedics included self-reported heart disease history, stroke history, hypertension, high cholesterol, diabetes, number of medications, fruit and vegetable intake $(\geq 1$ serving per day), salt intake (never, rarely, sometimes, often, always), physical activity ( $\geq 30 \mathrm{~min}$ of brisk walking daily), current smoking status, alcohol consumption (any versus none), body mass index (calculated from objectively measured weight and self-reported height), general self-reported health status (SRHS; poor, fair, good, very good/excellent), health-related quality of life (HRQoL) measures, and whether the participant had a family doctor. HRQoL measures were the five domains from the EQ-5D-3 L instrument: mobility, self-care, usual activities, pain/discomfort, and anxiety/depression [14]. All domains of HRQoL were categorized as "any problems" versus "none." For a detailed description of the assessments performed by the paramedics, see study protocol for the randomized controlled trial [10]. 


\section{Analysis}

Descriptive statistics were used to analyze the sociodemographic characteristics, health behaviours, and fallrelated outcomes of participants. Binary logistic regression models were created to analyze the association between the four outcome variables ('had fall in the past year', 'ever sought medical attention for a fall', 'fear of falling' and objectively measured 'fall risk' via TUG Test), and the independent variables, consisting of sociodemographic factors, including age, gender, ethnicity, level of education, and living alone, and the healthrelated indicators described above. For the model with 'fear of falling' as the outcome variable, 'had fall in the past year' was also included as an independent variable due to its association with 'fear of falling' in previous literature. Some variables, such as educational level, ethnicity, SRHS, and the HRQoL measures, were collapsed into fewer categories to account for small sample sizes observed with some response options and to minimize the number of variables in the models. Participants with missing responses for any of the independent variables were excluded from the analyses. All analyses were performed using IBM SPSS Statistics 17.0.

\section{Results}

A total of 595 participants (mean age $=73.23 \pm 9.18$ years) were included in this study. The majority of the full participant group was female (81.3\%), white $(86.7 \%)$, did not have a high school diploma $(50.0 \%)$, reported problems in mobility $(56.2 \%)$, experienced some pain or discomfort (69.2\%), had hypertension (63.5\%), and was obese (42.4\%). Based on the three screening questions, 326 participants were identified as being potentially at risk for falls. Of the 257 participants who completed the TUG test, 62 (26.8\%) were classified as "at-risk of falling" based on their TUG score. Reasons for not completing the TUG test varied, including concern for participant safety (e.g. relies on wheelchair for ambulation or has limited vision), temporary ailments (e.g. broken leg or recovering from surgery), or participant refusal (e.g. already had a walker and felt further evaluation was unnecessary). Among participants who completed the TUG test, $58.4 \%$ had fallen in the past year, $36.2 \%$ had ever sought medical attention for a fall and $65.8 \%$ had a fear of falling, compared to 34.5, 20.2 and $38.8 \%$, respectively, among all participants. Please see Table 1 for participant characteristics.

As described in Table 2, the binary logistic regression models revealed significant factors associated with each of the outcomes. The odds of having a fall in the previous year was significantly higher for individuals with mobility issues $(\mathrm{OR}=1.75,95 \% \mathrm{CI} 1.11-2.75)$ and significantly lower in individuals who consumed at least one serving of fruits and vegetables everyday $(\mathrm{OR}=0.55$, 95\% CI 0.37-0.83) or reported very good/excellent SRHS compared to those with poor SRHS (OR $=0.44,95 \%$ CI $0.21-0.97)$. The odds of seeking medical attention for a fall was significantly higher for individuals with mobility issues $(\mathrm{OR}=2.78,95 \% \mathrm{CI} 1.58-4.87)$ and significantly lower in individuals who were male $(\mathrm{OR}=0.50,95 \% \mathrm{CI}$ $0.25-0.98)$ or who reported fair $(\mathrm{OR}=0.38,95 \% \mathrm{CI}$ $0.18-0.81)$, good $(\mathrm{OR}=0.43,95 \%$ CI $0.20-0.89$ ) or very good/excellent $(\mathrm{OR}=0.34,95 \%$ CI $0.14-0.80)$ SRHS. The odds of having a fear of falling was significantly higher in individuals with mobility issues $(\mathrm{OR}=1.66,95 \%$ CI 1.05-2.62), those 85 years of age or older $(\mathrm{OR}=2.76$, 95\% CI 1.19-6.40), had any alcohol consumption (OR = 1.72 , 95\% CI 1.03-2.88), or had fallen in the past year $(\mathrm{OR}=2.33$, 95\% CI 1.55-3.50). Additionally, the odds of having a fear of falling was significantly lower in those who were male $(\mathrm{OR}=0.42,95 \% \mathrm{CI} 0.24-0.76)$ or reported having a SRHS of good (OR $=0.48,95 \%$ CI $0.24-0.99$ ) or very good/excellent ( $\mathrm{OR}=0.42,95 \% \mathrm{CI} 0.19-0.93)$. Finally, mobility issues $(\mathrm{OR}=3.68,95 \% \mathrm{CI} 1.12-12.60)$ and the presence of pain and discomfort $(\mathrm{OR}=4.56,95 \% \mathrm{CI} 1.31-$ 15.92) were significantly associated with higher fall risk among participants identified by the TUG test.

\section{Discussion}

This study determined that in this sample of older adults (aged 55 years and older) in public housing, the prevalence of falls in the past year was $34.5 \%$, which is substantially higher than the $19.8 \%$ observed among Canadian seniors aged 65 years and older [1]. This discrepancy in the occurrence of falls among public housing residents highlights the need for targeted interventions. One modifiable risk factor identified in this study and infrequently associated with fall history is daily consumption of fruits and vegetables, which was a protective factor in our study. Since low-income older adults are often at risk of having a poor diet, falls prevention interventions that include nutritional components or educational elements on healthy eating may be of merit. Nutritional risk has previously been identified as a determinant for falls specifically in frail older adults, [15] including factors such as ability to purchase and prepare food, unintended weight gain or loss, and other factors that could contribute to poor nutrition, however the consumption of fruits and vegetables was not part of that broad nutrition risk measure. Further research is needed to determine the extent to which diet quality can impact the postural stability of low-income older adults as well. Also, since daily consumption of fruits and vegetables was significantly associated with incidents of falls in the previous year but not with future fall risk, as measured using the TUG test, longitudinal research is needed to better understand this relationship.

Low SRHS and issues with mobility were also found to be significantly associated with history of falling in this population. These risk factors have been well-established 
Table 1 Demographic characteristics and health status indicators of all participants, participants who completed the TUG test, and participants at risk of falling

\begin{tabular}{|c|c|c|c|}
\hline Variable & $\begin{array}{l}\text { All Participants }(n=595) \\
\mathrm{n}(\%)^{\mathrm{a}}\end{array}$ & $\begin{array}{l}\text { Completed TUG Test }(n=257) \\
\mathrm{n}(\%)^{\mathrm{b}}\end{array}$ & $\begin{array}{l}\text { At Risk of Falling }(n=62) \\
\mathrm{n}(\%)^{c}\end{array}$ \\
\hline \multicolumn{4}{|l|}{ Gender } \\
\hline Male & $111(18.7)$ & $47(18.3)$ & $16(25.8)$ \\
\hline Female & $484(81.3)$ & $210(81.7)$ & $46(74.2)$ \\
\hline \multicolumn{4}{|l|}{ Age } \\
\hline $55-64$ & $127(21.3)$ & $52(20.2)$ & $13(21.0)$ \\
\hline $65-74$ & $215(36.1)$ & $90(35.0)$ & $14(22.6)$ \\
\hline $75-84$ & $195(32.8)$ & $86(33.5)$ & 19 (30.6) \\
\hline $85+$ & $58(9.7)$ & $29(11.3)$ & $16(25.8)$ \\
\hline \multicolumn{4}{|l|}{ Ethnicity } \\
\hline White & $516(86.7)$ & $237(92.2)$ & $57(91.9)$ \\
\hline Other & 79 (13.3) & $20(7.8)$ & $5(8.1)$ \\
\hline \multicolumn{4}{|l|}{ Education } \\
\hline Some high school & $289(50.0)$ & $134(52.3)$ & $37(59.7)$ \\
\hline High school diploma & $116(20.1)$ & $48(18.8)$ & $14(22.6)$ \\
\hline Some or completed post-secondary & $173(29.9)$ & $74(28.9)$ & $11(17.7)$ \\
\hline Lives Alone & $532(90.8)$ & $232(90.6)$ & $56(90.3)$ \\
\hline Fallen in the Past Year & $205(34.5)$ & $150(58.4)$ & $38(61.3)$ \\
\hline Ever Sought Medical Attention for a Fall & $120(20.2)$ & $93(36.2)$ & $30(48.4)$ \\
\hline Has a Fear of Falling & $231(38.8)$ & $169(65.8)$ & $50(80.6)$ \\
\hline Mobility Issues & $323(56.2)$ & $159(63.1)$ & $55(90.2)$ \\
\hline Self-Care Issues & $118(20.6)$ & $61(24.3)$ & $29(47.5)$ \\
\hline Issues Performing Usual Activities & $225(39.2)$ & $116(46.0)$ & $44(72.1)$ \\
\hline Pain/Discomfort & $398(69.2)$ & $185(73.4)$ & $54(88.5)$ \\
\hline Anxiety/Depression & $273(47.6)$ & $137(54.4)$ & $42(68.9)$ \\
\hline \multicolumn{4}{|l|}{ Number of Medications } \\
\hline None & $99(16.6)$ & $25(9.7)$ & $5(8.1)$ \\
\hline $1-4$ & $159(26.7)$ & $64(24.9)$ & $5(8.1)$ \\
\hline $5-9$ & $212(35.6)$ & $105(40.9)$ & $24(38.7)$ \\
\hline $10+$ & $125(21.0)$ & $63(24.5)$ & $28(45.2)$ \\
\hline \multicolumn{4}{|l|}{ Perceived Health State } \\
\hline Poor & $57(9.8)$ & $31(12.1)$ & $14(22.6)$ \\
\hline Fair & $162(27.9)$ & $82(31.9)$ & $23(37.1)$ \\
\hline Good & $222(38.3)$ & $97(37.7)$ & 19 (30.6) \\
\hline Very Good/Excellent & $139(24.0)$ & $47(18.3)$ & $6(9.7)$ \\
\hline Diabetes & $174(29.8)$ & $85(33.1)$ & $29(46.8)$ \\
\hline Heart Disease & $120(20.6)$ & $55(21.4)$ & $20(32.3)$ \\
\hline Hypertension & $366(63.5)$ & $169(66.0)$ & $46(74.2)$ \\
\hline High Cholesterol & $282(48.5)$ & $138(53.7)$ & $34(54.8)$ \\
\hline Stroke & $53(9.1)$ & $25(9.7)$ & $9(14.5)$ \\
\hline Physically Active (30 min per day) & $301(50.6)$ & $130(50.6)$ & $29(46.8)$ \\
\hline Fruits and Vegetables Everyday & $335(56.3)$ & $119(46.3)$ & $31(50.0)$ \\
\hline
\end{tabular}

Salt Intake 
Table 1 Demographic characteristics and health status indicators of all participants, participants who completed the TUG test, and participants at risk of falling (Continued)

\begin{tabular}{llll}
\hline Variable & All Participants $(n=595)$ & $\begin{array}{l}\text { Completed TUG Test }(n=257) \\
\mathrm{n}(\%)^{\mathrm{b}}\end{array}$ & $\begin{array}{l}\text { At Risk of Falling (n=62) } \\
\mathrm{n}(\%)^{\mathrm{c}}\end{array}$ \\
\hline Never & $201(34.7)$ & $95(37.1)$ & $28(45.2)$ \\
Rarely & $134(23.1)$ & $50(19.5)$ & $10(16.1)$ \\
Sometimes & $105(18.1)$ & $45(17.6)$ & $14(22.6)$ \\
Often & $55(9.5)$ & $26(10.2)$ & $2(3.2)$ \\
Always & $85(14.7)$ & $40(15.6)$ & $8(12.9)$ \\
Current Smoker & $150(25.8)$ & $70(27.2)$ & $10(16.1)$ \\
Consumes Any Alcohol & $114(19.6)$ & $61(23.8)$ & $12(19.4)$ \\
Has a Family Doctor & $527(88.6)$ & $234(91.1)$ & $59(95.2)$ \\
Body Mass Index & & $62(24.1)$ & $14(22.6)$ \\
Normal & $141(24.2)$ & $10(3.9)$ & $1(1.6)$ \\
Underweight & $18(3.1)$ & $72(28.0)$ & $15(24.2)$ \\
Overweight & $177(30.4)$ & $113(44.0)$ & $32(51.6)$ \\
Obese & $247(42.4)$ & & \\
\hline
\end{tabular}

Note: TUG Timed Up and Go Test, an objective assessment of fall risk; ${ }^{\mathrm{a}}$ missing data was less than $3.6 \%$ for each variable; ${ }^{\mathrm{b}}$ missing data was less than $2.4 \%$ for each variable; ${ }^{c}$ missing data was less than $1.7 \%$ for each variable

in the literature $[1,2,6]$. Similarly, mobility issues and pain and discomfort were associated with risk of falling as objectively measured by the TUG test. Factors such as living alone, number of medications and medical conditions, including diabetes, hypertension, stroke, and depression, were identified as risk factors for falls in the literature [6] but were non-significant in this study. This is likely due to the greater influence asserted by mobility and pain and discomfort, which may have masked the association of other variables.

The outcome variable of seeking medical attention for falls has not been extensively studied however the findings followed our expectations, particularly wherein females were more likely to seek medical care for falls. This is a general trend seen for healthcare utilization across all age groups and health concerns [16, 17]. In addition, women presenting at the emergency department following a fall are more likely to have a fracture or other injury requiring hospitalization, compared to men [18]; therefore, injury severity may contribute to sex differences in medical seeking behaviour following a fall. Similarly, the association of lower SRHS with greater odds of seeking medical attention after a fall may be explained by the fact that individuals with poorer health and chronic diseases are more likely to sustain severe injury during a fall [2]. SRHS has been widely reported as an important predictor of mortality and functional decline $[19,20]$. Consequently, it may be beneficial to assess older adults (55 years and older) with lower SRHS for fall risk as part of routine primary care.

Although fear of falling estimates in the literature are much more variable, ranging anywhere from 25 to $55 \%$, they are universally reported to be more prevalent in women and with increasing age [21-23], as was found in this study. Consistent with our results, self-reported health status and a history of falls are also commonly associated with a fear of falling [21, 22, 24]. A new finding in this study was the association between alcohol consumption and fear of falling among older adults in public housing. There is very limited research available on the association between alcohol consumption and fear of falling, and none with older adults. In Canada, older adults in the general population have a lower prevalence of alcohol use (71.1\%) compared to those $15-54$ years of age (79.9\%), but those who do consume alcohol are more likely to drink daily, compared to younger individuals (11.0\% versus $4.0 \%)$ [25]. Research suggests that older adults may use alcohol for medicinal purposes $[25,26]$. The prevalence of alcohol use among older adults in this public housing population was much lower (19.6\%), but the strong association of their alcohol use with fear of falling suggests that this relationship warrants further research.

A strength of this study is the ability to access and evaluate a hard to reach population. This study addresses a gap in the literature by identifying risk factors for falls among older adults of low SES and uses an objective validated measure of fall risk. Another strength of the study is the wide geographical representation of older adults in public housing throughout the province of Ontario.

Limitations of this study include a small sample size of 62 participants that were identified by the TUG test as being at risk of falling. This was in part because not all participants who were positively screened through the three questions performed the TUG test (e.g. participant 
Table 2 Odds ratios from binary logistic regression models for each fall-related outcome in older adults residing in public housing

\begin{tabular}{|c|c|c|c|c|}
\hline \multirow[t]{3}{*}{ Variable } & $\begin{array}{l}\text { Ever sought medical attention for a } \\
\text { fall }\end{array}$ & Had fall in the past year & Has fear of falling & At risk of falls ${ }^{a}$ \\
\hline & Yes $(n=116)$ vs No $(n=441)$ & $\begin{array}{l}\text { Yes }(n=196) \text { vs No }(n= \\
361)\end{array}$ & $\begin{array}{l}\text { Yes }(n=223) \text { vs No }(n= \\
334)\end{array}$ & $\begin{array}{l}\text { Yes }(n=61) \text { vs No }(n= \\
170)\end{array}$ \\
\hline & OR $(95 \% \mathrm{Cl})$ & OR $(95 \% \mathrm{Cl})$ & OR (95\% Cl) & OR $(95 \% \mathrm{Cl})$ \\
\hline \multicolumn{5}{|l|}{ Gender } \\
\hline Female & REF & REF & REF & REF \\
\hline Male & $0.50(0.25-0.98)$ & $0.99(0.58-1.69)$ & $0.42(0.24-0.76)$ & $1.80(0.45-4.45)$ \\
\hline \multicolumn{5}{|l|}{ Age } \\
\hline $55-64$ & REF & REF & REF & REF \\
\hline $65-74$ & $0.81(0.43-1.53)$ & $0.76(0.45-1.30)$ & $0.94(0.54-1.63)$ & $0.45(0.13-1.55)$ \\
\hline $75-84$ & $0.83(0.42-1.63)$ & $0.84(0.47-1.49)$ & $1.18(0.65-2.15)$ & $1.58(0.44-5.70)$ \\
\hline $85+$ & $0.89(0.35-2.24)$ & $0.84(0.37-1.87)$ & $2.76(1.19-6.40)$ & $4.07(0.77-21.50)$ \\
\hline \multicolumn{5}{|l|}{ Ethnicity } \\
\hline White & REF & REF & REF & REF \\
\hline Other & $0.53(0.22-1.29)$ & $0.54(0.27-1.07)$ & $0.87(0.44-1.71)$ & $3.26(0.60-17.61)$ \\
\hline \multicolumn{5}{|l|}{ Education level } \\
\hline Some high school & REF & REF & REF & REF \\
\hline High school diploma & $1.14(0.63-2.07)$ & $0.73(0.44-1.23)$ & $0.95(0.57-1.61)$ & $0.67(0.22-2.04)$ \\
\hline Any post-secondary & $1.23(0.72-2.08)$ & $0.75(0.48-1.19)$ & $0.91(0.57-1.45)$ & $0.46(0.15-1.37)$ \\
\hline Does not live alone & $1.31(0.53-3.24)$ & $1.90(0.90-4.02)$ & $0.77(0.37-1.59)$ & $1.04(0.21-5.06)$ \\
\hline \multicolumn{5}{|l|}{ Number of medications } \\
\hline 0 & REF & REF & REF & REF \\
\hline $1-4$ & $1.18(0.55-2.53)$ & $0.69(0.37-1.27)$ & $0.67(0.35-1.29)$ & $0.23(0.03-1.70)$ \\
\hline $5-9$ & $0.93(0.46-1.91)$ & $0.57(0.32-1.02)$ & $1.51(0.82-2.78)$ & $1.05(0.20-5.36)$ \\
\hline $10+$ & $1.08(0.48-2.41)$ & $1.00(0.52-1.95)$ & $1.70(0.84-3.41)$ & $1.62(0.30-8.80)$ \\
\hline Physically active daily & $1.06(0.67-1.67)$ & $1.17(0.79-1.73)$ & $0.89(0.60-1.33)$ & $2.09(0.88-4.96)$ \\
\hline Fruits and vegetables daily & $0.66(0.41-1.07)$ & $0.55(0.37-0.83)$ & $0.80(0.52-1.22)$ & $0.85(0.34-2.10)$ \\
\hline \multicolumn{5}{|l|}{ Salt intake } \\
\hline Never & REF & REF & REF & REF \\
\hline Rarely & $0.98(0.54-1.77)$ & $1.07(0.65-1.76)$ & $0.79(0.47-1.32)$ & $0.39(0.12-1.22)$ \\
\hline Sometimes & $1.23(0.66-2.30)$ & $0.87(0.50-1.52)$ & $0.80(0.45-1.43)$ & $2.12(0.66-6.81)$ \\
\hline Often & $0.96(0.40-2.30)$ & $1.37(0.68-2.79)$ & $1.05(0.50-2.20)$ & $0.29(0.05-1.86)$ \\
\hline Always & $0.85(0.42-1.76)$ & $0.75(0.41-1.38)$ & $1.16(0.63-2.13)$ & $0.47(0.13-1.70)$ \\
\hline \multicolumn{5}{|l|}{ Body Mass Index } \\
\hline Normal & REF & REF & REF & REF \\
\hline Underweight & $0.93(0.25-3.45)$ & $0.93(0.30-2.95)$ & $2.90(0.85-9.91)$ & $1.28(0.08-20.76)$ \\
\hline Overweight & $0.70(0.37-1.33)$ & $0.95(0.56-1.62)$ & $1.15(0.66-2.01)$ & $0.94(0.27-3.26)$ \\
\hline Obese & $0.63(0.34-1.18)$ & $0.64(0.38-1.09)$ & $1.31(0.75-2.28)$ & $2.38(0.74-7.67)$ \\
\hline \multicolumn{5}{|l|}{ Self-reported health } \\
\hline Poor & REF & REF & REF & REF \\
\hline Fair & $0.38(0.18-0.81)$ & $0.72(0.36-1.44)$ & $0.65(0.32-1.34)$ & $0.54(0.15-2.00)$ \\
\hline Good & $0.43(0.20-0.89)$ & $0.67(0.34-1.32)$ & $0.48(0.24-0.99)$ & $0.50(0.13-2.03)$ \\
\hline Very good/excellent & $0.34(0.14-0.80)$ & $0.44(0.21-0.97)$ & $0.42(0.19-0.93)$ & $0.43(0.09-2.13)$ \\
\hline Has heart disease & $1.51(0.88-2.58)$ & $1.16(0.72-1.86)$ & $0.61(0.37-1.01)$ & $1.45(0.54-3.89)$ \\
\hline Has hypertension & $1.06(0.64-1.76)$ & $0.90(0.59-1.39)$ & $0.89(0.57-1.38)$ & $1.38(0.53-3.56)$ \\
\hline
\end{tabular}


Table 2 Odds ratios from binary logistic regression models for each fall-related outcome in older adults residing in public housing (Continued)

\begin{tabular}{|c|c|c|c|c|}
\hline \multirow[t]{3}{*}{ Variable } & $\begin{array}{l}\text { Ever sought medical attention for a } \\
\text { fall }\end{array}$ & Had fall in the past year & Has fear of falling & At risk of falls ${ }^{a}$ \\
\hline & Yes $(n=116)$ vs No $(n=441)$ & $\begin{array}{l}\text { Yes }(n=196) \text { vs No }(n= \\
361)\end{array}$ & $\begin{array}{l}\text { Yes }(n=223) \text { vs No }(n= \\
334)\end{array}$ & $\begin{array}{l}\text { Yes }(n=61) \text { vs No }(n= \\
170)\end{array}$ \\
\hline & OR $(95 \% \mathrm{Cl})$ & OR $(95 \% \mathrm{Cl})$ & OR $(95 \% \mathrm{Cl})$ & OR $(95 \% \mathrm{Cl})$ \\
\hline Has high cholesterol & $1.21(0.75-1.95)$ & $1.30(0.86-1.96)$ & $1.43(0.94-2.17)$ & $0.44(0.17-1.13)$ \\
\hline Has diabetes & $1.24(0.72-2.13)$ & $1.34(0.84-2.13)$ & $0.75(0.46-1.23)$ & $1.30(0.50-3.35)$ \\
\hline Has stroke history & $0.64(0.28-1.45)$ & $0.88(0.45-1.70)$ & $1.25(0.63-2.48)$ & $1.78(0.44-7.26)$ \\
\hline Has mobility issues & $2.78(1.58-4.87)$ & $1.75(1.11-2.75)$ & $1.66(1.05-2.62)$ & $3.68(1.12-12.60)$ \\
\hline Has self-care issues & $1.50(0.83-2.73)$ & $1.39(0.82-2.37)$ & $1.36(0.78-2.35)$ & $1.81(0.63-5.19)$ \\
\hline Has usual care issues & $0.87(0.50-1.52)$ & $0.85(0.53-1.38)$ & $1.02(0.62-1.65)$ & $1.39(0.51-3.84)$ \\
\hline Has pain/discomfort issues & $0.89(0.52-1.53)$ & $1.14(0.73-1.80)$ & $1.23(0.77-1.95)$ & $4.56(1.31-15.92)$ \\
\hline $\begin{array}{l}\text { Has anxiety/depression } \\
\text { issues }\end{array}$ & $0.88(0.55-1.40)$ & $0.97(0.65-1.44)$ & $1.31(0.88-1.97)$ & $2.04(0.81-5.15)$ \\
\hline Currently smokes & $0.73(0.41-1.29)$ & $0.63(0.39-1.03)$ & $1.08(0.66-1.76)$ & $0.54(0.15-1.94)$ \\
\hline Consumes any alcohol & $1.48(0.83-2.62)$ & $1.40(0.85-2.30)$ & $1.72(1.03-2.88)$ & $1.22(0.41-3.60)$ \\
\hline Has a family doctor & $1.26(0.56-2.82)$ & $1.18(0.62-2.26)$ & $1.33(0.67-2.65)$ & $2.00(0.39-10.35)$ \\
\hline Had fall in the past year & - & - & $2.33(1.55-3.50)$ & - \\
\hline
\end{tabular}
and Go risk score

refusal or uses a wheelchair outside of their apartment), which may have led to an underestimation of the fall risk in this population. Moreover, cognitive impairments, which have shown to be significantly associated with fear of falling [27], were not assessed. Additionally, there have been inconsistent findings regarding the cutoff point and the ability of the TUG test to identify individuals at high risk of falls among different settings and populations [28]. However, it has been reported that the TUG test is of greater use in a less healthy and lower functioning population of older adults, similar to the participants in our study [29]. Finally, the cross-sectional design of this study prevents the temporality of associations from being established; for example, it cannot be determined whether fear of falling leads to a poor perceived health status or vice versa.

\section{Conclusion}

Falls in older adults are a complex public health issue that require a multifaceted approach to identify the risk factors and develop effective interventions to target these populations. This study presents novel findings conducted among older adults residing in public housing, a predominantly lowincome population that has largely been excluded from previous falls research. Our findings indicate a greater prevalence of falls and fear of falling exist among this population, suggesting that SES is intricately linked to an individual's risk of falling. Moreover, the unique risk factors that may predispose individuals to falls offer insight into the multifactorial underpinnings of falls. Consequently, as the Canadian population continues to age, further research that informs interventions tailored towards the social determinants of health of low-income older adults is needed.

\section{Abbreviations \\ ED: Emergency department; HRQOL: Health-related quality of life; SES: Socioeconomic status; SRHS: Self-reported health status; TUG: Timed-up- and-go \\ Acknowledgements \\ Not applicable. \\ Authors' contributions \\ MP, GA, RA, FM, JP were involved in study conceptualization and implementation. MP, GS, and GA analyzed and interpreted the participant data. All authors were involved in preparing the paper and approved the final manuscript. \\ Funding \\ This work was supported by the Hamilton Academic Health Sciences Organization and Canadian Institutes of Health Research under Grant \#133563. The funding body was not involved in the design of the study and collection, analysis, and interpretation of data and in writing the manuscript.}

\section{Availability of data and materials}

The data that support the findings of this study are not publicly available due to them containing information that could compromise participant privacy. De-identified, limited data will be shared by the lead author upon request.

\section{Ethics approval and consent to participate}

The Hamilton Integrated Research Ethics Board approved this study and consent to participate was obtained, in writing, from all participants: REB \#12-336.

\section{Consent for publication}

Not applicable.

Competing interests

The authors declare that they have no competing interests. 
Received: 8 April 2019 Accepted: 19 December 2019

Published online: 09 January 2020

\section{References}

1. Sibley KM, Voth J, Munce SE, Straus SE, Jaglal SB. Chronic disease and falls in community-dwelling Canadians over 65 years old: a population-based study exploring associations with number and pattern of chronic conditions. BMC Geriatr. 2014;14:22.

2. Public Health Agency of Canada. Seniors' Falls in Canada: Second Report. Cat: HP25-1/2014E. Ottawa, ON: Her Majesty the Queen in Right of Canada, as represented by the Minister of Health, 2014

3. Gill TM, Murphy TE, Gahbauer EA, Allore HG. Association of injurious falls with disability outcomes and nursing home admissions in community-living older persons. Am J Epidemiol. 2013;178:418-25.

4. Tomita Y, Arima K, Tsujimoto R, Kawashiri S, Nishimura T, Mizukami S, et al. Prevalence of fear of falling and associated factors among Japanese community-dwelling older adults. Medicine (Baltimore). 2018;97:e9721.

5. Kumar A, Carpenter H, Morris R, lliffe S, Kendrick D. Which factors are associated with fear of falling in community-dwelling older people? Age Ageing. 2014;43:76-84.

6. Deandrea S, Lucenteforte E, Bravi F, Foschi R, La Vecchia C, Negri E. Risk factors for falls in community-dwelling older people. Epidemiology. 2010;21:658-68.

7. Agarwal G, Habing K, Pirrie M, Angeles R, Marzanek F, Parascandalo J. Assessing health literacy among older adults living in subsidized housing: a cross-sectional study. Can J Public Heal. 2018;109:401-9.

8. Ionescu-Ittu R, McCusker J, Ciampi A, Vadeboncoeur A-M, Roberge D, Larouche $\mathrm{D}$, et al. Continuity of primary care and emergency department utilization among elderly people. CMAJ. 2007;177:1362-8.

9. Wachelder JJH, van Drunen I, Stassen PM, Brouns SHA, Lambooij SLE, Aarts $\mathrm{MJ}$, et al. Association of socioeconomic status with outcomes in older adult community-dwelling patients after visiting the emergency department: a retrospective cohort study. BMJ Open. 2017;7:e019318.

10. Agarwal G, McDonough B, Angeles R, Pirrie M, Marzanek F, McLeod B, et al. Rationale and methods of a multicentre randomised controlled trial of the effectiveness of a community health assessment Programme with emergency medical services (CHAP-EMS) implemented on residents aged 55 years and older in subsidised seniors' housing buildings in Ontario. Canada BMJ Open. 2015;5:e008110.

11. Geriatrics Interprofessional Interorganizational Collaboration. The assessment and Management of Falls in primary care. Kingston, ON: Centre for Studies in Aging \& Health; 2008

12. American Geriatrics Society, British Geriatrics Society, American Academy of Orthopaedic Surgeons Panel on Fall Prevention. Guidelines for the prevention of falls in older adults. J Am Geriatr Soc. 2001;49:664-72.

13. Shumway-Cook A, Brauer S, Woollacott M. Predicting the probability for falls in community-dwelling older adults using the timed up \& go test. Phys Ther. 2000;80:896-903.

14. Szende A, Oppe M, Devlin N. EQ-5D value sets: inventory, comparative review and user guide. Dordrecht, The Netherlands: Springer; 2007.

15. Johnson CS. The association between nutritional risk and falls among frail elderly. J Nutr Health Aging. 2003;7:247-50.

16. Stevens JA, Ballesteros MF, Mack KA, Rudd RA, DeCaro E, Adler G. Gender differences in seeking care for falls in the aged Medicare population. Am J Prev Med. 2012;43:59-62.

17. Curtis $L$, MacMinn WJ. Health care utilization in Canada: twenty-five years of evidence. Can Public Policy. 2008;34:65-87.

18. Stevens JA, Sogolow ED. Gender differences for non-fatal unintentional fall related injuries among older adults. Inj Prev. 2005;11:115-9.

19. Idler EL, Benyamini Y. Self-rated health and mortality: a review of twentyseven community studies. J Health Soc Behav. 1997;38:21-37.

20. Lee $Y$. The predictive value of self assessed general, physical, and mental health on functional decline and mortality in older adults. J Epidemiol Community Heal. 2000;54:123-9.

21. Malini FM, Lourenço RA, Lopes CS. Prevalence of fear of falling in older adults, and its associations with clinical, functional and psychosocial factors: the frailty in Brazilian older people-Rio de Janeiro study. Geriatr Gerontol Int. 2016;16:336-44

22. Murphy SL, Williams CS, Gill TM. Characteristics associated with fear of falling and activity restriction in community-living older persons. J Am Geriatr Soc. 2002;50:516-20.
23. Scheffer AC, Schuurmans MJ, van Dijk N, van der Hooft T, de Rooij SE. Fear of falling: measurement strategy, prevalence, risk factors and consequences among older persons. Age Ageing. 2008;37:19-24.

24. da Cruz DT, Duque RO, Leite ICG. Prevalence of fear of falling, in a sample of elderly adults in the community. Rev Bras Geriatr Gerontol. 2017;20:309-18.

25. Flint AJ, Merali Z, Vaccarino FJ, editors. Substance use in Canada: improving quality of life: substance use and aging. Ottawa, ON: Canadian Centre on Substance Use and Addiction; 2018.

26. Aira M, Hartikainen S, Sulkava R. Drinking alcohol for medicinal purposes by people aged over 75: a community-based interview study. Fam Pract. 2008;25:445-9.

27. Grenier S, Richard-Devantoy S, Nadeau A, Payette MC, Benyebdri F, Duhaime $M M B$, et al. The association between fear of falling and motor imagery abilities in older community-dwelling individuals. Maturitas. 2018;110:18-20.

28. Barry E, Galvin R, Keogh C, Horgan F, Fahey T. Is the timed up and go test a useful predictor of risk of falls in community dwelling older adults: a systematic review and meta-analysis. BMC Geriatr. 2014;14:14.

29. Schoene D, Wu SMS, Mikolaizak AS, Menant JC, Smith ST, Delbaere K, et al. Discriminative ability and predictive validity of the timed up and go test in identifying older people who fall: systematic review and meta-analysis. J Am Geriatr Soc. 2013;61:202-8.

\section{Publisher's Note}

Springer Nature remains neutral with regard to jurisdictional claims in published maps and institutional affiliations.
Ready to submit your research? Choose BMC and benefit from:

- fast, convenient online submission

- thorough peer review by experienced researchers in your field

- rapid publication on acceptance

- support for research data, including large and complex data types

- gold Open Access which fosters wider collaboration and increased citations

- maximum visibility for your research: over $100 \mathrm{M}$ website views per year

At BMC, research is always in progress.

Learn more biomedcentral.com/submissions 